https://doi.org/10.48009/1_iis_2007_185-191

\title{
A COMPARISON OF TWO COMPUTER LITERACY TESTING APPROACHES
}

\author{
Ruth Robbins, University of Houston-Downtown, robbinsr@uhd.edu \\ Zehai Zhou, University of Houston-Downtown, zhouz@uhd.edu
}

\begin{abstract}
Although computer literacy is hard to define and means different things to different people, the advancement of information and communication technologies and the ubiquitous computing environment have made it a necessity for everyone to be computer literate. Computer literacy is a fundamental part of undergraduate education. The assessment of computer literacy remains to be a challenging issue faced by educators. This study focuses on a comparison of two computer literacy testing approaches. Two testing tools, the Computer Skills Placement (CSP) test and the Prentice Hall Train \& Assess IT (TAIT) testing tool, were selected and investigated. A qualitative comparison of two testing tools was made. The differences in basic computer skills or sets of knowledgebase covered were discussed and the advantages and disadvantages of each testing tools were examined. As a case study, a quantitative comparison of two testing tools was done using data collected from a freshman-level computer literacy course in fall 2006 semester. In this freshman-level computer literacy course required for all majors at an urban university, students were tested on their computer literacy knowledgebase and computer skills at the end of the semester utilizing the two testing tools. Our study analyzed the performance of 132 students in this course. Correlations between the scores from the two testing instruments were analyzed. A paired sample $t$ test was conducted to compare the students' performance among the examination scores. For the colleges that plan to use Computer Skills Placement (CSP) test or Prentice Hall Train \& Assess IT (TAIT) test as a testing tool for credit-by-exam, we made some recommendations on setting the cut scores. Limitations of this study were discussed and future works and directions were included.
\end{abstract}

Keywords: computer literacy, computer education, teaching tools, computer skills, assessment

\section{INTRODUCTION}

The impact of information and communication technology is really profound and revolutionary. It is one of the major driving forces for businesses of all sizes today. It has dramatically changed our global society in general, and the ways in which organizations conduct business and how people live and work in particular. We are in an information age and more and more people live and work within the context of information and communication technology. In today's rapidly changing society and workplace, and global markets, it is more important than ever for a citizen and/or employee to understand the technology around them. Creighton et al. [9] argued that computers are here to stay and that the explosion of technology and the abundance of accessible computers in every phase of a person's life have made it a necessity for everyone to be computer literate. Johnson et al. [19] asserted that stakeholders, such as future employers, parents, and educators, have raised their expectations [see also 1] of college graduates in the area of computer literacy and that computer skills and understanding are especially critical for business management graduates, who are expected to use computer technology as a tool in every aspect of their careers.

Although most people agree that computer literacy is essential for a citizen to function well in our information society, the definition of computer literacy is hard to make. The term "computer literacy" means different things to different people $[15,20,26]$. Different group of people - students, teachers, and employers - have different ideas about what computer literacy means [19]. Coffee [6] claimed that defining computer literacy is like trying to define "life", "space" or "energy" - pursuits that may be entertaining but don't really bring much to the bottom line or shorten your to-do-list although he also observed that "computer literacy may be hard to define, but computer illiterate is costly".

Computer literacy is a fundamental part of undergraduate curriculum today [14]. Bogan [3] reported that college students fell short in demonstrating the ICT literacy skills necessary for success in college and the workplace. ETS reached these conclusions after evaluating the responses of 6,300 students who took the company's ICT (information and communication technology) Literacy Assessment in 2006. For other interesting studies and information on computer literacy, please refer to $[2,4,10,13,16,17,23,28$, and 29]. 
The assessment of computer literacy remains to be a challenging issue faced by educators. The purpose of this study was to assess student's computer literacy using different testing approaches. In particular, the objectives of this research were:

- To make a qualitative comparison of the two testing tools: the Computer Skills Placement (CSP) test and the Prentice Hall Train \& Assess IT (TAIT) testing tool. The differences in terms of basic computer skills or sets knowledgebase covered were discussed, and the advantages and disadvantages of each testing tools were examined.

- $\quad$ To determine if there is any correlation between the testing scores of the TAIT test and the testing scores of the CSP test.

- $\quad$ To determine if there is any difference between the mean testing scores of the TAIT test and the mean testing scores of the CSP test.

- $\quad$ To determine the cut-score for the TAIT test if is used as a testing tool for "credit-by-exam", and if applicable, to determine the cut-score for the CSP test if can be used as a testing tool for “credit-by-exam”.

\section{BACKGROUND}

\section{The University}

Located in Southwest Texas, in the heart of downtown Houston, University of HoustonDowntown (UHD) is a primarily undergraduate only commuter university. Until recently, there were no graduate programs. Now, there are four graduate programs: Master of Science in Criminal Justice, Master of Science in Professional Writing and Technical Communication, Master of Arts in Teaching, and Master of Security Management for Executives. There are 37 different undergraduate programs.

The student population, as of the UHD Fact Book [27]: 37.44\% - Hispanic, 25.99\% Black (nonHispanic), 23.65\% White (non-Hispanic), 9.79\% Asian or Pacific Islanders, 2.92\% - International Students (non-resident aliens), 0.20\% - American Indian or Alaska Natives, and $0 \%$ are classified as Race/ethnicity unknown. These numbers reflect the diversity of the surrounding greater Houston metropolitan area which is composed more than 2 million residents. Of these residents: $37 \%$ are of Hispanic origin (regardless of race), 2.3\% are Black,
49.27\% are White, 0.44 are Native American, 5.31\% are Asian American, $0.06 \%$ are Pacific Islanders, $16.46 \%$ are classified as Other Races, and 3.15\% are classified as being a part of two or more races.

The average age of students at UHD is 27 years of age with 3 students under age 17 and up to 4 students over the age of 65 . The other students are within that range. $59.34 \%$ of students are female and $40.66 \%$ are male.

Because this is a commuter campus with many nontraditional students, many of the UHD students are self-sufficient, have families for which they are financially responsible, and work fulltime or parttime, while enrolled in classes taking a part-time (less than 12 semester hours) or fulltime (12 or more semester hours) course load. Because of this work and/or family commitments that many students share, it often takes more than the traditional four years for them to complete their 4 year undergraduate degree at UHD.

Additionally, legislators within the state of Texas have become concerned that graduation requirements at state of Texas public, 4-year institutions are requiring students to remain in school longer than 4 years, thus requiring a greater financial burden for Texas taxpayers. Consequently, the 120 hour rule which stipulates that the graduation requirement for a baccalaureate degree be amended to 120 credit hours is being discussed [25].

All students at the University of Houston Downtown are required to satisfy a core curriculum that includes courses in areas such as: Math, English, History, Government, Science, and other basic courses. In addition, all students must satisfy a Computer Literacy/Introduction to Computers course. Satisfying this course requirement can be undertaken by: taking an Introduction to Computers course thru Computer Information Systems, Computer Science, Humanities, or Engineering Technology at UHD; transferring an equivalent course from one of the community colleges or other four-year schools; or completing some equivalency exam. This equivalency exam requirement, though listed in the catalog, has not been implemented with appropriate procedures. One of the purposes of this paper is to relate how this university undertakes the task of implementing a test-out procedure for an Introduction to Computers/Computer Literacy course through the Computer Information Systems (CIS) discipline in the College of Business. 


\section{The Course}

This Introduction to Computers (CIS 1301) class is a freshman level class. It includes coverage of basic computer concepts (as $50 \%$ of the class), and as the other $50 \%$ of the class: Microsoft Windows, Word, Excel, PowerPoint, Access; and HTML \& Internet concepts. Students meet in a classroom environment that allows each student access to a computer in a 1:1 (one student: one computer) setting. The students also utilize a training and assessment tool developed by Prentice-Hall: Train \& Assess IT.

\section{The Prentice Hall Train \& Assess IT (TAIT) Testing Tool}

The students also utilize a training and assessment tool developed by Prentice-Hall: Train \& Assess IT. Interim training on Word, Excel, PowerPoint and Access during the semester is enhanced with TAIT training simulation modules. Quizzes, semester exams and end-of-semester final exams are developed with TAIT, requiring students to answer Word, Excel, PowerPoint \& Access simulation questions and/or multiple choice questions in a testing environment.

The Prentice Hall Train \& Assess IT (TAIT) testing tool is one of the Teaching, Training, and Assessing tools used in many colleges, vocational schools, or high schools. Other widely used testing tools in this group include SAM from Thomson/Course Technology [8] and SimNet from McGraw-Hill [21]. The major characteristics of this group of tools are that they are normally well designed and extremely flexible. They contain many different skills and knowledge bases and the contents from different subjects can be added, deleted or customized. One pitfall of this group of testing tools is that the correct or viable answer by a student may be judged "incorrect" in rare situation because the simulated environment may not recognize that way of accomplishing the task. The instructor can set many different kinds of parameters and control how the tests are administrated.

\section{The Computer Skills Placement (CSP) Test}

The comparison tool for testing was the Computer Skills Placement (CSP) assessment [7]. CSP was introduced at the June (2006) ACCUPLACER conference. It was developed in collaboration with the CollegeBoard and ACCUPLACER and as a component of the International Computer Driving Licence (ICDL) (also called the European Computer Driving Licence (ECDL)) Certification [12] program and is based on the world's leading basic computer skills program that currently has over 6 million participants in over 140 countries. It consists of 70 multiple choice questions, with 10 questions on each of the following seven areas:

- Basic Concepts of IT

- Using the Computer and Managing Files

- Word Processing

- $\quad$ Spreadsheets

- Databases

- Presentations

- Information and Communication

The reason for comparison testing was to determine the passing score for students who might choose to opt out of the course by taking the exam, without taking the course. No schools, to date, (according to the information we received) were using it as a CIS test-out, prior to our testing it for that purpose.

Another testing tool in this group is Internet and Computing Core Certification (IC ${ }^{3}$ ). Internet and Computing Core Certification is designed to validate an individual's basic computer skills and Internet knowledge to promote success in school, work, and life [5]. This group of testing tools normally includes a set of skills or knowledge base against which the test takers would be assessed. Although the companies that provide the tests often claim that the tests can be customized and tailored or modified to fit the particular needs of the adopters, it seems that the customization is quite limited (if at all possible) compared with first group of testing tools. The instructors would not have much to set up and administration of the exam is easier.

\section{RESEARCH METHODOLOGY}

The quantitative part of our research centered upon the following research questions: Is there any correlation between the testing scores of the TAIT test and the testing scores of the CSP test? Is there any difference between the mean testing scores of the TAIT test and the mean testing scores of the CSP test?

Pearson's correlation coefficient (r) is used to measure the strength of the linear relationship between two test scores. The statistical significance of $r$ is tested using a t-test. The hypotheses for this test are:

$$
\begin{aligned}
& H_{0}: r=0 \\
& H_{a}: r<>0
\end{aligned}
$$


A low p-value for this test (less than 0.05 for example) means that there is evidence to reject the null hypothesis in favor of the alternative hypothesis, or that there is a statistically significant relationship between the two test scores.

On the other hand, the paired-sample t test is used to compare the means of two variables within a single group. In other words, a paired t-test is normally used to compare means on the same or related subject over time or in differing circumstances. For our study, it was used to see if there is a statistically significant difference between the CSP test scores and the TAIT scores among the 132 students in CIS 1301.

The paired t-test is actually a test that the difference between the two observations is 0 . So, if $\mathrm{D}$ represents the difference between observations, the hypotheses are:

$\mathrm{H}_{\mathrm{o}}: \mathrm{D}=0$ (the difference between the two observations is 0 )

$$
\mathrm{H}_{\mathrm{a}}: \mathrm{D}<>0 \text { (the difference is not } 0 \text { ) }
$$

The test statistic is $t$ with $n-1$ degrees of freedom. If the p-value associated with $t$ is low $(<0.05)$, there is evidence to reject the null hypothesis. Thus, one would have evidence that there is a difference in means across the paired observations.

To test these hypotheses, data were collected in fall 2006 in four sections of CIS1301.

\section{RESULTS}

At the end of the fall 2006 semester, students in four different sections of CIS 1301 were given two final exams: 70 questions from the TAIT test bank and the CSP exam, which, also consists of 70 questions. The TAIT exam was given first. Upon conclusion of the TAIT exam, students were given codes to allow them to access the CSP exam and they, subsequently, answer the CSP exam questions. As an incentive, students were made to believe that both exams would be used in calculating their final exam grade and final semester grade.

All the related data were input into SPSS 15, a statistical software package. Data were analyzed using descriptive statistics to get the demographic summary of the 132 students, and using correlation and paired-samples $\mathrm{T}$ test in inferential statistics to test the two pair of hypotheses.
Our study analyzed the performance of 132 students (from freshman to senior) in those four sections of CIS1301 course. The demographic data for students taking the exams are shown in Table 1. The sample population had more females (58.3\%) than males (41.7\%). Although the class is a freshman level course, students from other class level (including transferring or returning students) may also take the class. In our sample, freshman, sophomore, junior and senior students account for $47.7 \%, 31.1 \%, 11.4 \%$ and $9.8 \%$ of the total students, respectively.

A t test was performed to test each of the two pair of hypotheses. The first pair of hypotheses tested whether there is any correlation between the testing scores of the TAIT test and the testing scores of the CSP test. A p-value was calculated and any value less than 0.05 was to be rejected. Hypothesis 1 was rejected on this basis. In other words, there is evidence to reject the null hypothesis in favor of the alternative hypothesis, or that there is a statistically significant relationship between the two test scores (please refer to Table 2 for details).

The second pair of hypotheses tested whether there is a statistically significant difference between the CSP test scores and the TAIT scores. A p-value was calculated and any value less than 0.05 was to be rejected. Hypothesis 2 was on this basis, rejected. In other words, there is evidence to reject the null hypothesis in favor of the alternative hypothesis, or that there is a statistically significant difference between the CSP test scores and the TAIT scores (please refer to Table 3 and Table 4 for details).

\section{DISCUSSION}

An evaluation was made of the linear relationship between CSP test scores and TAIT test scores using Pearson's correlation. An analysis using Pearson's correlation coefficient indicates a statistically significant linear relationship between TAIT test score and CSP test score $r(130)=0.724, p<0.001$. For these data, the mean (SD) for test CSP test is 57.76(9.395) and for the TAIT 67.45 (9.640). Since the p value is close to 0.000 , it seems that the two test scores are highly correlated. Although we felt that the tests similar to TAIT (e.g., SimNet from McGrawHill or SAM from Thomson/Course Technology) may be superior to CSP (or similar test tools) after our qualitative analysis, both testing tools could be viable options and used to certain degree. We would recommend TAIT (or similar test) if the price is not an issue and there are instructors available to customize the tests. 
Table 1. Demographics

\begin{tabular}{|c|c|c|c|c|c|c|c|}
\hline & & & \multicolumn{4}{|c|}{ Class } & \multirow[b]{2}{*}{ Total } \\
\hline & & & freshman & sophomore & junior & senior & \\
\hline \multirow[t]{8}{*}{ Gender } & Female & Count & 36 & 27 & 7 & 7 & 77 \\
\hline & & \% within Gender & $46.8 \%$ & $35.1 \%$ & $9.1 \%$ & $9.1 \%$ & $100.0 \%$ \\
\hline & & \% within Class & $57.1 \%$ & $65.9 \%$ & $46.7 \%$ & $53.8 \%$ & $58.3 \%$ \\
\hline & & \% of Total & $27.3 \%$ & $20.5 \%$ & $5.3 \%$ & $5.3 \%$ & $58.3 \%$ \\
\hline & Male & Count & 27 & 14 & 8 & 6 & 55 \\
\hline & & \% within Gender & $49.1 \%$ & $25.5 \%$ & $14.5 \%$ & $10.9 \%$ & $100.0 \%$ \\
\hline & & \% within Class & $42.9 \%$ & $34.1 \%$ & $53.3 \%$ & $46.2 \%$ & $41.7 \%$ \\
\hline & & \% of Total & $20.5 \%$ & $10.6 \%$ & $6.1 \%$ & $4.5 \%$ & $41.7 \%$ \\
\hline \multirow[t]{4}{*}{ Total } & & Count & 63 & 41 & 15 & 13 & 132 \\
\hline & & \% within Gender & $47.7 \%$ & $31.1 \%$ & $11.4 \%$ & $9.8 \%$ & $100.0 \%$ \\
\hline & & \% within Class & $100.0 \%$ & $100.0 \%$ & $100.0 \%$ & $100.0 \%$ & $100.0 \%$ \\
\hline & & \% of Total & $47.7 \%$ & $31.1 \%$ & $11.4 \%$ & $9.8 \%$ & $100.0 \%$ \\
\hline
\end{tabular}

Table 2. Paired Samples Correlations

\begin{tabular}{|ll|r|r|c|}
\hline & N & Correlation & Sig. \\
\hline Pair 1 & $\begin{array}{l}\text { CSP_Score \& } \\
\text { TAIT_Score }\end{array}$ & 132 & .724 & $.000(* *)$ \\
\hline
\end{tabular}

Table 3. Paired Samples Statistics

\begin{tabular}{|rl|r|r|r|r|}
\hline & Mean & N & Std. Deviation & $\begin{array}{c}\text { Std. Error } \\
\text { Mean }\end{array}$ \\
\hline Pair 1 & CSP_Score & 57.76 & 132 & 9.395 & .818 \\
& TAIT_Score & 67.45 & 132 & 9.640 & .839 \\
\hline
\end{tabular}

Table 4. Paired Samples Test

\begin{tabular}{|c|c|c|c|c|c|c|c|}
\hline \multicolumn{5}{|c|}{ Paired Differences ((CSP_Score - TAIT_Score) } & \multirow{3}{*}{$\mathrm{t}$} & \multirow{3}{*}{ df } & \multirow{3}{*}{$\begin{array}{l}\text { Sig. (2- } \\
\text { tailed) }\end{array}$} \\
\hline \multirow[t]{2}{*}{ Mean } & \multirow[t]{2}{*}{$\begin{array}{l}\text { Std. } \\
\text { devia. }\end{array}$} & \multirow[t]{2}{*}{$\begin{array}{l}\text { Std. error } \\
\text { Mean }\end{array}$} & \multicolumn{2}{|c|}{$\begin{array}{l}\text { 95\% Confidence Interval of the } \\
\text { difference }\end{array}$} & & & \\
\hline & & & Lower & Upper & & & \\
\hline-9.689 & 7.071 & 615 & -10.907 & -8.472 & -15.743 & 131 & $.000(* *)$ \\
\hline
\end{tabular}

** Difference is significant at the 0.01 level (2-tailed).

A cut-score needs to be set if one of the tests is used as a bypass test for computer literacy requirement or is used as a testing tool for "credit-by-exam". Setting cut-scores for those purposes have been, and will continue to be a challenging and difficult issue. Cut score-setting is a process that relies heavily on the judgment and needs and capacity of the educators involved. We suggest that the cut-score is set to be equal to the mean + standard deviation. Therefore, for the CSP testing tool, we recommend that the cutscore be set to $57.76+9.395=67.155$ or 67 , and for the TAIT testing tool, the cut-score be set to $67.45+9.640=77.090$ or 77 .
In this paper, we focused on two testing tools, the Computer Skills Placement (CSP) test and the Prentice Hall Train \& Assess IT (TAIT) testing tool. We think that they are two good representatives from two groups of testing tools. Yet in the market, there is another group of testing tools: Information and Communication Technology (ICT) Literacy Assessment [18]. Two leading examples are the iSkills - Information and Communication Technology Literacy Test by ETS (Education Testing Service) [11] and on-Screen Test for ICT at Key Stage 3 [22, 24]. iSkills (formerly known as ICT Literacy Assessment), developed by ETS, is a comprehensive 
test of ICT proficiency, originally developed for higher-education environment. iSkills divides ICT literacy into seven key proficiencies: define, access, manage, integrate, evaluate, create, and communicate. It is scenario-based (as compared with TAIT, part of which is simulation-based). It measures technological literacy-how well students can apply computer skills into real-life scenarios that require students to sift through oftentimes multiple information sources or applications (Websites, email, charts, spreadsheets, databases, search engine, etc.), decide which sources to use, and use them proficiently. While we agree that the goals are lofty, the idea is very interesting, and the intensions are good, we think that ICT Literacy Assessment is much more involved and the students' performance may be affected significantly by some other factors (e.g., cognitive skills, critical and logical thinking skills, etc.). It seems difficult at this stage to compare the three approaches (e.g., compare iSkills, TAIT, and CSP) and analyze them either quantitatively or qualitatively.

\section{CONCLUSIONS}

After studying the contents and making a qualitative comparison of the two testing tools: the Computer Skills Placement (CSP) test and the Prentice Hall Train \& Assess IT (TAIT) testing tool, we felt that there are some differences in terms of basic computer skills or sets knowledgebase covered in those two test tools. As for the price, the results from our initial inquiries seem to favor the CSP test over the TAIP test: the former costs about \$29/person/test and the latter around $\$ 60$ (which, however, includes the right to use all the materials and tests in Train and Assess IT for a whole semester).

Based upon the results of our quantitative study, we concluded that the testing scores of the TAIT test and the testing scores of the CSP test are highly correlated. We also concluded that there is a significant difference between the mean testing scores of the TAIT test and the mean testing scores of the CSP test as administrated in UHD in fall 2006.

\section{LIMITATIONS AND FUTURE WORK}

This study centered on a comparison of two computer literacy testing approaches. As examples for the two approaches, two testing tools, the Computer Skills Placement (CSP) test and the Prentice Hall Train \& Assess IT (TAIT) testing tool, were selected and investigated. This study is still preliminary and future work may be needed or necessary. For example, we did not have chances to record students' technical background (such as computer experiences), their majors (computer related, technical or non-technical), their ethic background, their attitude toward computer, information and communication technologies, or their social-economic status that may or may not make some difference in students' performance. We did not collect information about students' age or type (traditional vs. non-traditional) which may also be factors affecting students' testing scores. In addition, we did not an administrate pretest in the beginning of the semester and therefore could not analyze if and how the students' computer literacy proficiency changes before and after the semester and during the semester. Therefore, we may wish to extend the study to incorporate pre-tests and include more students from all colleges of the university, collecting additional data on students' age, type, and other background information.

In the near future, we are planning to examine if there are any the differences in test results between female and male students and if there are any differences in test results between different student classifications (year in college) for the TAIT test and the CSP test , both separately and combined. It seems that the University of Houston-Downtown is planning to move forward and implement the test-out procedure in this fall or next year using the CSP test. We believe that it is important to continue monitoring closely how appropriate the CSP test is for assessing students' computer literacy proficiency and make adjustment if necessary. We may also explore the possibility of a pilot study on utilizing the ICT assessment instrument by ETS or other institutions and if possible, compare the test results from TAIT, CSP, and the ICT assessment tests.

\section{ACKNOWLEDGEMENTS}

The authors would like to acknowledge and thank Burton Burrus for his assistance in administrating the tests and for collecting the data.

\section{REFERENCES}

1. Bartholomew, K.W. (2004). Computer literacy: is the emperor still exposed after all these years? Journal of Computing Sciences in Colleges, 20(1), 323-331.

2. Bennett, J.F. and Cooper, P.A. (2004). The computer literacy course: putting it all together. Information Systems Education Journal, 2(6), 39.

3. Bogan, K. (2006). College Students Fall Short in Demonstrating the ICT Literacy Skills Necessary for Success in College and the Workplace. 
Available:

http://wwwdev.hawaii.edu/lilo/ver5/content/info _lit_students_falling_short.pdf

4. Burger, A. and Blignaut, P. (2004). A computer literacy course may initially be detrimental to students' attitudes towards computers. Proceedings of the SAICSIT conference, Stellenbosch, Western Cape, South Africa, 1014.

5. Certiport, http://www.certiport.com/portal/DesktopDefault. aspx

6. Coffee, P. (2006) Computer literacy isn't kid stuff. eWeek, 23(18), $55 . \quad$ Available: http://www.eweek.com/article2/0,1759,1956817, 00.asp.

7. Computer Skills Placement, http://www.csplacement.com/

8. Course Technology, SAM, http://samcentral.course.com/

9. Creighton, W., Kilcoyne, M., Tarver, R. and Wright, S. (2006). Computer literacy levels of students enrolling in a post-secondary computer applications/information technology course. Information Technology, Learning, and Performance Journal, 24(1), 15-23.

10. Edmiston, E. and McClelland, M. (2001). A conversation about ensuring computer literacy of first-year students. Journal of Computing Sciences in Colleges, 16(2), 306-316.

11. Education Testing Service, http://www.ets.org/

12. European Computer Driving Licence Foundation, available: http://www.ecdl.com/publisher/index.jsp

13. Foster, K., DeNoia, L. and Dannelly, S. (2006). Reengineering a computer literacy course. Journal of Computing Sciences in Colleges, 22(2), 197-202.

14. Gupta, G.K. (2006). Computer literacy: essential in today's computer-centric world. Inroads - the SIGCSE Bulletin, 38(2), 115-119.

15. Hoffman, M., Blake, J. (2003). Computer literacy: today and tomorrow. Journal of Computing Sciences in Colleges, 18(5), 221-233.

16. Hoffman, M., Blake, J., McKeon, J., Leone, S., Schorr, M. (2005). A critical computer literacy course. Journal of Computing Sciences in Colleges, 20(5), 163-175.
17. Hoffman, M.E. and Vance, D.R. (2005). Computer literacy: what students know and from whom they learned it. Proceedings of the ACM SIGCSE conference, St. Louis, Missouri, USA, 356-360.

18. Honey, M., Pasnik, S. and Fasca, C. (2006). Is having the right answer enough? Developing new forms of assessment for $21^{\text {st }}$ century learning. Threshold, Spring 2006, 22-26. Available:

http://www.ciconline.org/thresholdspring06.

19. Johnson, D.W., Bartholomew, K.W. and Miller, D. (2006). Improving computer literacy of business management majors: a case study. Journal of Information Technology Education, 5, 77-94.

20. Mason, J. and McMorrow, R. (2006). YACLD (Yet Another Computer Literacy Definition). Journal of Computing Sciences in Colleges, 21(5), 94-100.

21. McGraw-Hill Irwin, SimNet, http://www.mhhe.com/cit/simnet/simnet_home_ page.htm

22. National Assessment Agency. The essential guide to the key stage 3 ICT test. Available: http://www.naa.org.uk/naaks3/

23. Owens, B.B. (2003). Ethics and the Internet: a novel approach to computer literacy. Journal of Computing Sciences in Colleges, 18(4), 4-10.

24. Qualifications and Curriculum Authority (QCA), http://www.qca.org.uk/7280.html

25. TEXAS POLITICS PROJECT. Available: http://texaspolitics.laits.utexas.edu/html/pr/speak er_series_files/transcripts/zaffirini.txt

26. Stiller, E. and LeBlanc, C. (2006). From computer literacy to cyber-literacy. Journal of Computing Sciences in Colleges, 21(6), 4-13.

27. University of Houston Downtown Fact Book. (2006). Available: www.uhd.edu/about/facts.htm

28. van Dyke, C. (1987). Talking "computer literacy" literally. The Communications of ACM, 30(5), 366-374.

29. Werner, L. (2005). Redefining computer literacy in the age of ubiquitous computing. Proceedings of the ACM SIGTE conference, Newark, New Jersey, USA, 95-99. 